\title{
Adaptive gamification strategies for education: a systematic literature review
}

\author{
Vinícius Lopes ${ }^{1}$, Wendel Souto Reinheimer ${ }^{1}$, Roseclea Duarte Medina $^{1}$, \\ Giliane Bernardi ${ }^{1}$, Felipe Becker Nunes ${ }^{2}$ \\ ${ }^{1}$ Universidade Federal de Santa Maria (UFSM) - Av. Roraima n ${ }^{\circ} 1000$ \\ Caixa Postal 5082 - 97.105-900 - Santa Maria - RS - Brazil \\ ${ }^{2}$ Antonio Meneghetti Faculdade (AMF) \\ Est. Recanto Maestro n 338 - CEP 97200-000 - Restinga Sêca - RS - \\ \{vlopes, wsouto, rose, giliane\}@inf.ufsm.br, nunesfbegmail.com
}

\begin{abstract}
Gamification elements are frequently used in learning environments as a means to motivate and engage students. Adaptive gamification, a more recent approach, attempts to maximize the expected learning objectives by adapting these gamification elements to the needs of each user. In this paper, we present a systematic review of adaptive gamification in educational contexts aiming to understand how these adaptive features work, what they adapt and which strategies they adopt. We identified 16 papers that describe different adaptive gamification strategies for different learning topics, based on factors like user input, user experience, and player typology.
\end{abstract}

Resumo. Elementos de gamificação são frequentemente usados em ambientes de aprendizagem como método para motivar e engajar estudantes. Recentemente, a gamificação adaptativa vem surgindo como forma de maximizar os objetivos de aprendizagem esperados ao adaptar elementos de gamificação às necessidades dos usuários. Neste artigo, é apresentada uma revisão sistemática sobre gamificação adaptativa em ambientes educacionais, buscando compreender como essa adaptação acontece, o que é adaptado e quais estratégias são adotadas. Foram identificados 16 artigos que descrevem diferentes estratégias de gamificação adaptativa para diferentes tópicos de aprendizagem, baseandose em fatores como interações e experiência do usuário e perfis de jogador.

\section{Introduction}

With the advent of new technologies providing different means to access information, students are becoming uninterested by traditional teaching and learning methods. In recent years, gamification, which is characterized by the use of game elements in non-game contexts [Deterding et al. 2011], has been presented as a strategy to instigate and engage learners, helping them achieve their goals. Gamification is widely known as the use of principles from game development and game design outside of the gaming context, to enhance user experience and foster engagement [Kapp 2012].

However, the use of gamification in educational contexts does not always achieve the expected results. This can happen due to many factors, such as lack of interest in games, the difficulty for educators to interact with electronic games, or even generic 
strategies that do not take into account the user profile [Silva et al. 2018]. For gamification to happen efficiently, it has to be adaptable to each user. It is necessary to understand the needs of the target audience, define learning objectives, build strategies, and identify available resources in order for this adaptation process to happen [Huang and Soman 2013].

With that in mind, there is a need to understand and categorize what has been developed in the literature about adaptive gamification, as well as its applicability in educational contexts. This paper describes a systematic literature review in order to fulfill the need for this research.

\section{Gamification}

In [Kapp 2012], gamification is described not only as the inclusion of game elements in various contexts but as the careful and thoughtful application of game thinking to solve problems and promote learning using all the elements that are appropriate in a given context. According to [Werbach and Hunter 2012], gamification elements can be divided into three categories based on their abstraction level: dynamics, mechanics and components. These elements range from virtual points, badges and leaderboards to narrative, challenges and relationships. The application of these elements can take various combinations, therefore, careful analysis of a particular situation's demands is the key to success in a gamification project [Werbach and Hunter 2012].

Thus, faced with the infinity of possibilities and applications in several areas of human activity, gamification emerges as a relevant alternative in the educational field, replacing the passive methods of teaching and learning used in most schools [Fardo 2013]. However, most gamified environments adopt a "one-size-fits-all" approach in their design, which does not take the individual needs of each user into account [Orji et al. 2018]. While interacting with a learning environment, individuals have different expectations and are motivated by different factors [Yee 2006]. Therefore, gamification should be adaptable and customizable for the user.

\subsection{Adaptive Gamification}

Adaptive Gamification can be defined as a strategy that seeks the maximization of the expected objectives of individuals, by prioritizing their needs and preferences in a gamified environment [Codish and Ravid 2014]. Meaningful Gamification as described in [Nicholson 2012] also corresponds to the characteristics of adaptive gamification, which prioritizes the users' needs. It focuses on flexibilization and customization of elements and dynamics for different types of users in order to promote unique interactions.

The adaptation of gamified systems to each user enables engagement, allows problem-solving on specific topics, and helps users achieve their goals more efficiently [Tondello et al. 2016]. A determining factor for educational systems to achieve their purposes is a clear understanding of who their target audience is (i.e., who the learners are), their needs and preferences, combined with the context in which the program is being delivered [Huang and Soman 2013].

A systematic mapping was conducted in [Filho et al. 2018], to analyze and comprehend difficulties of using gamification strategies. While answering one of the questions addressed in their study, namely "What kinds of difficulties are encountered using gamification as a strategy of interaction?", the authors recognized problems when implementing 
VIII Congresso Brasileiro de Informática na Educação (CBIE 2019)

Anais do XXX Simpósio Brasileiro de Informática na Educação (SBIE 2019)

gamification elements while not considering a specific context in their application. Additionally, it is noted that the identification of a user profile categorized by player typology can be an effective strategy to achieve maximum involvement of the learners, as well as maximize the knowledge acquired by them.

\subsection{Player Typologies}

Several studies were carried out aiming to identify and categorize players in what is commonly known as "player types" or "player profiles", these studies aim to synthesize several behaviors portrayed during a game. One of the oldest and most popular models is presented by [Bartle 1996], in 1996, which describes four profiles for players of MultiUser Dungeons (MUDs) games: Achiever, Explorer, Killer, and Socialiser.

A model proposed by [Yee 2006] describes three central motivations for Multiplayer Online Role-Playing Games (MMORPGs), with ten sub-components: Achievement (advancement, mechanics, competition), Social (socializing, relationship, teamwork), and Immersion (discovery, role-playing, customization, escapism). However, both of these models focus on specific game genres, not representing the full range of players from other genres.

In [Ferro et al. 2013], the authors divided the players into five categories: Dominant, Objectivist, Humanist, Inquisitive and Creative. In this model, the classification was made by combining the traits and personality types of each player with elements and game mechanics, so that these can be used to inform the design of gamified projects, enabling a more engaging and motivating experience for the user. In the model developed by [Nacke et al. 2011], called BrainHex, seven archetypes of players were identified, in which neurobiological aspects are taken into account in conjunction with literature searches of patterns and emotions evoked by games: Seeker, Survivor, Daredevil, Mastermind, Conqueror, and Socialiser.

Finally, a model called Hexad Scale was proposed by [Tondello et al. 2016], which separates players into six categories: Philanthropists, Socialiser, Free Spirit, Achiever, Player, and Disruptor. This model suggests that particular or external factors can motivate and engage users. Therefore these user types are representations of intrinsic and extrinsic motivation of individuals. Unlike other models, BrainHex and the Hexad Scale can be adapted to different gamification contexts without bias from a specific game genre.

\section{Methodology}

For this research, it was decided to do a Systematic Literature Review (SLR). As defined by [Kitchenham et al. 2010], SLR is a research methodology where all empirical studies on a particular topic are aggregated in a systematic, easily repeatable and unbiased way. This process allows a better understanding of the subject and provides answers to research questions related to it.

At first, we defined our research questions, inclusion and exclusion criteria, research databases and keywords which allowed us to generate a specific search string to use on those databases. Subsection 3.1 details this process. After that, using the search string generated, a search in all the databases was performed, resulting in 324 papers. Those papers were submitted to a 3-step filtering process and an evaluation to assert their 
VIII Congresso Brasileiro de Informática na Educação (CBIE 2019)

Anais do XXX Simpósio Brasileiro de Informática na Educação (SBIE 2019)

quality regarding the research questions. After this step, detailed in subsections 3.2 and 3.3, 16 papers remained. The data analysis of these papers is described in section 4 .

\subsection{Planning}

For this research on adaptive gamification in educational contexts, four Research Questions (RQ) were created, designed to better understand the subject and how it has been approached in recent years. The questions were the following:

- RQ1: How is adaptive gamification being applied in the educational context?

- RQ2: Which learning topics are being addressed with the use of adaptive gamification?

- RQ3: Which gamification strategies are being used in the educational context?

- RQ4: How are these adaptive gamification strategies for education being tested and evaluated?

Systematic research was carried out on several databases for papers regarding the subject in order to answer these questions. The databases selected were, in alphabetical order, ACM Digital Library, Elsevier (ScienceDirect), Google Scholar, IEEE Xplore, Scopus and Web of Science. In order to narrow down the search for papers in these databases, Inclusion and Exclusion Criteria (IC and EC respectively) were created.

\section{Inclusion Criteria:}

- The paper describes the use of adaptive gamification in an educational context.

- The paper includes keywords of both core concepts or any of their synonyms in its structure.

- The paper is written either in English or Portuguese.

- The paper was published between 2012 and 2018.

\section{Exclusion Criteria:}

- The paper does not describe adaptive gamification or does not use it on an educational context.

- The paper only contains theoretical studies, without development or implementation of any kind.

- The paper is a secondary or tertiary study.

- The paper is written in a different language than English or Portuguese.

- The paper was not published between 2012 to 2018.

Knowing that the core concepts of this research were Adaptive Gamification and Education, Table 1 was created with keywords containing synonyms to these concepts, in order to generate the main search string to be used on research databases.

Table 1. Keywords

\begin{tabular}{|c|c|}
\hline Core Concepts & Synonyms \\
\hline Adaptive Gamification & $\begin{array}{c}\text { Smart Gamification, Smart Serious Games, } \\
\text { Intelligent Game Based Learning, Smart Game } \\
\text { Based Learning, Human Centered Gamification }\end{array}$ \\
\hline Education & Teaching, Learning \\
\hline
\end{tabular}


VIII Congresso Brasileiro de Informática na Educação (CBIE 2019)

Anais do XXX Simpósio Brasileiro de Informática na Educação (SBIE 2019)

From Table 1, the following search string was generated: ("Adaptive Gamification" OR "Smart Gamification" OR "Smart Game Based Learning" OR "Intelligent Game Based Learning" OR "Human Centered Gamification") AND ("Teaching" OR "Learning" OR "Education"). An alternate version of this string with the same terms in Portuguese was also generated. This string was adapted without altering its terms in order to work efficiently on the search engine of all databases.

\subsection{Filtering}

After using the string on all research databases, which was the first stage of the filtering process, 324 papers returned. Our team of researchers went through two more stages of filtering to assert their relevance to this research. In the next stage, the title and abstract of all 324 papers was read, using the inclusion and exclusion criteria to define which ones would continue into the next stage. After this process, 63 papers remained. In the following stage, the full-text of these 63 papers was read, again using the inclusion and exclusion criteria to establish their relevance for this research even further. In the end, 16 papers remained. Table 2 shows how many papers remained after each stage, categorized by their database.

Table 2. Papers by database per step

\begin{tabular}{|c|c|c|c|}
\hline $\begin{array}{c}\text { Research } \\
\text { Databases }\end{array}$ & $\begin{array}{c}\text { Search } \\
\text { Results }\end{array}$ & $\begin{array}{c}\text { Title and } \\
\text { Abstract }\end{array}$ & $\begin{array}{c}\text { Full } \\
\text { Text }\end{array}$ \\
\hline ACM & 6 & 4 & 1 \\
\hline Elsevier & 1 & 1 & 1 \\
\hline Google Scholar & 302 & 51 & 12 \\
\hline IEEE & 2 & 2 & 2 \\
\hline Scopus & 4 & 1 & 0 \\
\hline Web of Science & 9 & 4 & 0 \\
\hline Total & 324 & 63 & 16 \\
\hline
\end{tabular}

\subsection{Evaluation}

The 16 remained papers were evaluated using five evaluation criteria (EV) created in order to determinate quality of data, clarity of text and relevance to this research. The criteria is described below.

- EV1: Are the research objectives clear?

- EV2: Is there a proper description of the context in which adaptive gamification has been applied?

- EV3: Is there clarity in the adaptive gamification strategies described in the research?

- EV4: Does the research describe processes for developing and implementing these strategies?

- EV5: Are there validation and evaluation processes for the gamification strategies described in the research?

To quantify this evaluation, the answers to these questions were scored as 1 , for "yes", 0.5 for "partly", and 0 for "no". Table 3 shows the final score of all 16 papers after this process. 
VIII Congresso Brasileiro de Informática na Educação (CBIE 2019)

Anais do XXX Simpósio Brasileiro de Informática na Educação (SBIE 2019)

Table 3. Paper evaluation score

\begin{tabular}{|c|c|c|c|c|c|c|c|}
\hline PAPER & REFERENCE & EV1 & EV2 & EV3 & EV4 & EV5 & TOTAL \\
\hline P01 & [Klock et al. 2016] & 1 & 1 & 1 & 1 & 1 & 5 \\
\hline P02 & [Smith et al. 2017] & 1 & 1 & 1 & 1 & 1 & 5 \\
\hline P03 & [Henry et al. 2018] & 1 & 0 & 0 & 1 & 1 & 3 \\
\hline P04 & [Ning 2018] & 1 & 1 & 1 & 1 & 0 & 4 \\
\hline P05 & [Škuta and Kostolányová 2018] & 1 & 0.5 & 1 & 0.5 & 0 & 3 \\
\hline P06 & [Lavoué et al. 2018] & 1 & 1 & 1 & 1 & 1 & 5 \\
\hline P07 & [Min et al. 2014] & 1 & 1 & 0 & 1 & 0 & 3 \\
\hline P08 & [Knutas et al. 2016] & 1 & 1 & 1 & 1 & 0 & 4 \\
\hline P09 & [Hasan and Akhter 2014] & 1 & 1 & 1 & 0.5 & 1 & 4.5 \\
\hline P10 & [Jianu and Vasilateanu 2017] & 1 & 0.5 & 0.5 & 1 & 1 & 4 \\
\hline P11 & [Jagušt et al. 2018] & 1 & 1 & 1 & 1 & 1 & 5 \\
\hline P12 & [Vesin et al. 2018] & 1 & 0 & 0.5 & 1 & 1 & 3.5 \\
\hline P13 & [Ghali et al. 2015] & 1 & 0 & 0 & 1 & 1 & 3 \\
\hline P14 & [Knutas et al. 2017] & 1 & 1 & 1 & 0.5 & 0 & 3.5 \\
\hline P15 & [Kamnardsiri et al. 2016] & 1 & 1 & 0 & 1 & 1 & 4 \\
\hline P16 & [Paiva et al. 2016] & 1 & 1 & 1 & 1 & 1 & 5 \\
\hline
\end{tabular}

\section{Results}

By analyzing the data collected from these 16 papers, all four research questions were answered. Therefore, in this section we will present our contributions regarding the researched subject.

RQ1: How is adaptive gamification being applied in the educational context? From this research, it was evident that gamification has different approaches and interpretations when it comes to being adaptive. Some authors apply gaming features to already existing learning environments, like [Lavoué et al. 2018], where a learning environment called Project Voltaire, used to teach French spelling and grammar, uses different gamification elements, like score, hints, progress, and leaderboards with different intensity based on the user's gamer profile.

Others, like [Ghali et al. 2015] and [Henry et al. 2018], use sensors to perceive data from the user in order to adapt gamification features more efficiently. In [Ghali et al. 2015] a machine learning model uses sensors like electroencephalography, eye tracking, and facial expression recognition to predict the actions of a player in an educational chemistry game called Lewispace.

In [Henry et al. 2018] a framework is described that integrates Serious Games and Internet of Things (IoT) devices, in what it calls Smart Serious Games (SSG). This expression is also used in [Smith et al. 2017] where a modular framework is used to develop a game with the Unity engine called MAVEN, aimed to teach math to army veterans.

The study presented in [Kamnardsiri et al. 2016] describes the development of an Intelligent Game-Based System, that uses Xbox 360's Kinect paired up with the Unity engine, and teaches sign language by detecting the player's movements.

What can be observed from all these different approaches is that there's no consensus as to what the adaptive quality of gamification should be. Some authors 
VIII Congresso Brasileiro de Informática na Educação (CBIE 2019)

Anais do XXX Simpósio Brasileiro de Informática na Educação (SBIE 2019)

(as seen in [Smith et al. 2017], [Ghali et al. 2015], and [Kamnardsiri et al. 2016]) believe it comes from IoT devices and sensors to detect user's input and predict behavior, while others (as seen in [Klock et al. 2016], [Smith et al. 2017], [Lavoué et al. 2018], and [Paiva et al. 2016]) believe it comes from detecting the user's profile and learning context in order to adapt gamification elements.

RQ2: Which learning topics are being addressed with the use of adaptive gamification? Most of the studies analyzed in this research applied adaptive gamification techniques to the teaching and learning of STEM (Science, Technology, Engineering and Mathematics). In [Klock et al. 2016] a gamified learning environment was designed to teach algorithms to graduate students. In [Smith et al. 2017] a serious game was developed to teach math to army veterans. In [Lavoué et al. 2018] and [Jianu and Vasilateanu 2017] adaptive gamification was implemented in learning environments to teach Computer Science students from middle school and graduation, respectively.

Other studies focused on adaptive gamification techniques designed for teaching and learning languages, like [Lavoué et al. 2018] that uses a gamified learning environment to teach French spelling and grammar, and [Hasan and Akhter 2014] that applies smart gamification into a Facebook application called Wishdom, designed to English learning.

Although most of those studies suggest that their platforms can be used in different contexts and with different learning topics, none of them designed adaptive gamification elements or strategies based on the learning topic itself, which could potentially be a valid adaptive gamification strategy.

RQ3: Which gamification strategies are being used in the educational context? In this research different adaptive gamification strategies were identified. In [Ning 2018] the authors present a design method for building a gamification system by adapting user interface, procedure, and nature of the system using tools, rules, and goals adapted to each user. In [Paiva et al. 2016], the authors study student interactions with MeuTutor, a gamified online learning environment, in order to assist teachers and tutors in decision-making regarding student learning experience.

Some studies use already established models of player typologies in their adaptive gamification systems. In [Škuta and Kostolányová 2018] the authors suggest the use of a questionnaire or a tutorial level in order to classify the user using Bartle's player typology. In [Knutas et al. 2016] the same player typology is used to define profile clusters derived from Bartle's four player types. These profile clusters are, in turn, used to define adaptive gamification features. The study presented in [Lavoué et al. 2018] uses BrainHex as a model for user profiling, establishing a matrix of elements scoring their relevance for each player type. While in [Knutas et al. 2017], the authors used the Hexad Scale as part of a context-aware and personalized gamification ruleset for collaborative environments.

It was observed that the adaptive process based on player typology is usually considered in the early stages of user interaction with a gamified learning environment. This process could prove to be more effective if player types were adapted continually, not only analyzing user input in the beginning but also its behaviour throughout the entire time interacting with the environment. 
RQ4: How are these adaptive gamification strategies for education being tested and evaluated? Different approaches were used when testing and evaluating adaptive gamification strategies in an educational environment. Five papers gathered data from sensors and real-life scenario observation of an implemented strategy. Four other papers collected their data from simulations of these real-life scenarios. The preferred method for evaluating the efficiency of an adaptive gamification strategy was through the use of questionnaires, as it was applied in eight papers. Five papers did not disclose in full detail their research validation and evaluation process, either because it described research in progress or a proposal for adaptive gamification, and therefore couldn't be categorized.

\section{Conclusion and Future Work}

This paper described a systematic literature review of adaptive gamification on educational contexts. The goal was to understand how these adaptive features work, what they adapt and which strategies they adopt. We identified 16 papers with different approaches and understandings of the concept. Some papers perceive adaptive gamification as a sensor-based context-aware environment that adapts its gamification elements for improved user engagement. But the major part categorizes the user based on existing player typologies, for further adaptation of these elements. On that note, Bartle's player types seem to be the most common typology used, despite its limitations.

From this work, it becomes clear that more consistent patterns and definitions of adaptive gamification need to be established to maximize the effectiveness of gamified learning environments. Aside from sensorial data, context-awareness, and initial user profiling, other factors like adaptability to learning topics and continuous player type profiling should also be considered as strategies for adapting gamification elements to learning contexts.

\section{References}

Bartle, R. (1996). Hearts, clubs, diamonds, spades: Players who suit muds. Journal of MUD research, 1(1):19.

Codish, D. and Ravid, G. (2014). Adaptive approach for gamification optimization. In 2014 IEEE/ACM 7th International Conference on Utility and Cloud Computing, pages 609-610. IEEE.

Deterding, S., Khaled, R., Nacke, L. E., and Dixon, D. (2011). Gamification: Toward a definition. In CHI 2011 gamification workshop proceedings, volume 12. Vancouver BC, Canada.

Fardo, M. L. (2013). A gamificação aplicada em ambientes de aprendizagem. RENOTE, 11(1).

Ferro, L. S., Walz, S. P., and Greuter, S. (2013). Towards personalised, gamified systems: an investigation into game design, personality and player typologies. In Proceedings of The 9th Australasian Conference on Interactive Entertainment: Matters of Life and Death, page 7. ACM.

Filho, R., Silva, H., and Inocêncio, A. C. (2018). Um mapeamento sistemático sobre fatores que podem influenciar na eficiência da gamificação. In Brazilian Symposium 
VIII Congresso Brasileiro de Informática na Educação (CBIE 2019)

Anais do XXX Simpósio Brasileiro de Informática na Educação (SBIE 2019)

on Computers in Education (Simpósio Brasileiro de Informática na Educação-SBIE), volume 29, page 506.

Ghali, R., Ouellet, S., and Frasson, C. (2015). Lewispace: An educational puzzle game combined with a multimodal machine learning environment. In Joint German/Austrian Conference on Artificial Intelligence (Künstliche Intelligenz), pages 271-278. Springer.

Hasan, M. M. and Akhter, M. (2014). Design and development of english learning facebook application based on platform as a service (paas) by using smart gamification. Global Journal of Computer Science and Technology.

Henry, J., Tang, S., Hanneghan, M., and Carter, C. (2018). A framework for the integration of serious games and the internet of things (iot). In 2018 IEEE 6th International Conference on Serious Games and Applications for Health (SeGAH), pages 1-8. IEEE.

Huang, W. and Soman, D. (2013). Gamification of education. Research Report Series: Behavioural Economics in Action, Rotman School of Management, University of Toronto.

Jagušt, T., Botički, I., and So, H.-J. (2018). Examining competitive, collaborative and adaptive gamification in young learners' math learning. Computers \& Education, 125:444-457.

Jianu, E. M. and Vasilateanu, A. (2017). Designing of an e-learning system using adaptivity and gamification. In 2017 IEEE International Systems Engineering Symposium (ISSE), pages 1-4. IEEE.

Kamnardsiri, T., Hongsit, L.-o., Khuwuthyakorn, P., and Wongta, N. (2016). The development of an intelligent game-based system for learning sign language with kinect. In European Conference on Games Based Learning, page 304. Academic Conferences International Limited.

Kapp, K. (2012). The Gamification of Learning and Instruction: Game-based Methods and Strategies for Training and Education. Pfeiffer essential resources for training and HR professionals. Wiley.

Kitchenham, B., Pretorius, R., Budgen, D., Brereton, O. P., Turner, M., Niazi, M., and Linkman, S. (2010). Systematic literature reviews in software engineering-a tertiary study. Information and software technology, 52(8):792-805.

Klock, A. C. T., Gasparini, I., and Pimenta, M. S. (2016). 5w2h framework: a guide to design, develop and evaluate the user-centered gamification. In Proceedings of the 15th Brazilian Symposium on Human Factors in Computing Systems, page 14. ACM.

Knutas, A., Ikonen, J., Maggiorini, D., Ripamonti, L., and Porras, J. (2016). Creating student interaction profiles for adaptive collaboration gamification design. International Journal of Human Capital and Information Technology Professionals (IJHCITP), 7(3):47-62.

Knutas, A., van Roy, R., Hynninen, T., Granato, M., Kasurinen, J., and Ikonen, J. (2017). Profile-based algorithm for personalized gamification in computer-supported collaborative learning environments. In GHITALY@ CHItaly. 
VIII Congresso Brasileiro de Informática na Educação (CBIE 2019)

Anais do XXX Simpósio Brasileiro de Informática na Educação (SBIE 2019)

Lavoué, E., Monterrat, B., Desmarais, M., and George, S. (2018). Adaptive gamification for learning environments. IEEE Transactions on Learning Technologies, 12(1):16-28.

Min, W., Mott, B., and Lester, J. (2014). Adaptive scaffolding in an intelligent gamebased learning environment for computer science. In Proceedings of the Workshop on AI-supported Education for Computer Science (AIEDCS) at the 12th International Conference on Intelligent Tutoring Systems, pages 41-50.

Nacke, L. E., Bateman, C., and Mandryk, R. L. (2011). Brainhex: preliminary results from a neurobiological gamer typology survey. In International conference on entertainment computing, pages 288-293. Springer.

Nicholson, S. (2012). A user-centered theoretical framework for meaningful gamification. 8.0, Madison, USA.

Ning, B. (2018). A ux-driven design method for building gamification system. In International Conference of Design, User Experience, and Usability, pages 112-124. Springer.

Orji, R., Tondello, G. F., and Nacke, L. E. (2018). Personalizing persuasive strategies in gameful systems to gamification user types. In Proceedings of the $2018 \mathrm{CHI}$ Conference on Human Factors in Computing Systems, page 435. ACM.

Paiva, R., Bittencourt, I. I., Tenório, T., Jaques, P., and Isotani, S. (2016). What do students do on-line? modeling students' interactions to improve their learning experience. Computers in Human Behavior, 64:769-781.

Silva, H., Inocêncio, A. C., et al. (2018). Um mapeamento sistemático sobre fatores que podem influenciar na eficiência da gamificação. In Brazilian Symposium on Computers in Education (Simpósio Brasileiro de Informática na Educação-SBIE), volume 29, page 506.

Škuta, P. and Kostolányová, K. (2018). Adaptive aproach to the gamification in education. DIVAI 2018.

Smith, K., Shull, J., Shen, Y., Dean, A., and Heaney, P. (2017). A framework for designing smarter serious games. In International Conference on Smart Education and Smart ELearning, pages 263-294. Springer.

Tondello, G. F., Wehbe, R. R., Diamond, L., Busch, M., Marczewski, A., and Nacke, L. E. (2016). The gamification user types hexad scale. In Proceedings of the 2016 annual symposium on computer-human interaction in play, pages 229-243. ACM.

Vesin, B., Mangaroska, K., and Giannakos, M. (2018). Learning in smart environments: user-centered design and analytics of an adaptive learning system. Smart Learning Environments, 5(1):24.

Werbach, K. and Hunter, D. (2012). For the win: How game thinking can revolutionize your business. Wharton Digital Press.

Yee, N. (2006). Motivations for play in online games. CyberPsychology \& behavior, 9(6):772-775. 